\author{
Marquette University \\ e-Publications@Marquette
}

College of Nursing Faculty Research and

Publications

Nursing, College of

$5-2014$

\title{
Psychometric Properties of the Resourcefulness Scale Among Caregivers of Persons With Autism Spectrum Disorder
}

Abir K. Bekhet

Marquette University, abir.bekhet@marquette.edu

Jaclene Zauszniewski

Case Western Reserve University

Follow this and additional works at: https://epublications.marquette.edu/nursing_fac

Part of the Nursing Commons

\section{Recommended Citation}

Bekhet, Abir K. and Zauszniewski, Jaclene, "Psychometric Properties of the Resourcefulness Scale Among Caregivers of Persons With Autism Spectrum Disorder" (2014). College of Nursing Faculty Research and Publications. 266.

https://epublications.marquette.edu/nursing_fac/266 
Marquette University

e-Publications@Marquette

\title{
Nursing Faculty Research and Publications/College of Nursing
}

This paper is NOT THE PUBLISHED VERSION; but the author's final, peer-reviewed manuscript. The published version may be accessed by following the link in the citation below.

Western Journal of Nursing Research, Vol. 36, No. 5 (October 21, 2013): 685-702. DOI. This article is (C) SAGE Publications and permission has been granted for this version to appear in $\underline{\mathrm{e}}-$ Publications@Marquette. SAGE Publications does not grant permission for this article to be further copied/distributed or hosted elsewhere without the express permission from SAGE Publications.

\section{Psychometric Properties of the Resourcefulness Scale Among Caregivers of Persons with Autism Spectrum Disorder}

\author{
Abir K. Bekhet \\ Marquette University College of Nursing Milwaukee, WI, USA \\ Jaclene A. Zauszniewski \\ Case Western Reserve University, Cleveland, $\mathrm{OH}$, USA
}

\begin{abstract}
Caregiving for children with autism spectrum disorder (ASD) can be very costly to caregivers' wellbeing. Resourcefulness interventions have shown increases in positive health outcomes. However, before delivering the intervention, there should be a reliable and a valid measure to test resourcefulness. The psychometric properties of the Resourcefulness Scale (RS) have not been examined among ASD caregivers. This study examined the psychometrics of the 28 -item RS in a convenience sample of 204 ASD caregivers. A Cronbach's alpha of .91 showed the internal consistency of the RS. Construct validity was supported by the emergence of two dimensions of resourcefulness (personal and social) in a confirmatory factor analysis and by substantial intercorrelations between the
\end{abstract}


two subscales $(r=.48, p<.001)$. Findings suggested the reliability and validity of RS among ASD caregivers, which is a necessary step toward implementing resourcefulness interventions to help ASD caregivers to deal with their stress and improve their quality of life.

\section{Keywords}

mental health, clinical focus, caregivers, population focus behavior/symptom focus, instrument development

In the United States, 1 out of 88 persons are affected with autism spectrum disorder (ASD; Centers for Disease Control and Prevention, 2012). ASD is a complex neurological and developmental disorder that influences a person's communication and his or her ability to interact socially (Karst \& Van Hecke, 2012). Persons with ASD can be aggressive, overactive, self-injurious, and can demonstrate repetitive and stereotyped behaviors (Karst \& Van Hecke, 2012; Matson \& Fodstad, 2009). ASD symptoms appear before age 3 and affect individuals throughout their life span (American Psychiatric Association, 2000). More importantly, ASD affects not only the diagnosed person but also his or her caregivers, families, and the community. There is ample evidence that caregiving for persons with ASD can lead to numerous physical and psychological problems (Altiere \& Von Kluge, 2009; Benson, Karlof, \& Siperstein, 2008; Phetrasuwan \& Miles, 2009).

A review of recent literature shows that ASD caregivers report depressive symptoms as a result of the burden of providing care to persons with ASD (Carter, Martinez-Pedraza, \& Gray, 2009; Ekas, Lickenbrock, \& Whitman, 2010). Caregiver burden can result from many factors, including the child's challenging behaviors and the caregiver's lack of social interactions, financial problems, and worry about the future (Carbone, Behl, Azor, \& Murphy, 2010; Montes \& Halterman, 2007).

Previous research demonstrates that greater resourcefulness is associated with more adaptive functioning and greater life satisfaction (Bekhet, Zauszniewski, \& Wykle, 2008; Boonpongmanee, Zauszniewski, \& Morris, 2003; Huang et al., 2010). Resourcefulness is a cognitive-behavioral repertoire of self-control skills that are accompanied by one's ability to adapt effectively with adverse situations (personal resourcefulness) or to seek help from others when one is unable to function independently (social resourcefulness; Zauszniewski, Bekhet, \& Suresky, 2008).

Previous research on resourcefulness has focused on various populations, including diabetic females (Zauszniewski \& Chung, 2001), pregnant women (Boonpongmanee et al., 2003), children (Zauszniewski, Chung, Chang, \& Krafcik, 2002), older adults with chronic conditions (Zauszniewski, Chung, \& Krafcik, 2001), and older adults who have relocated to retirement communities (Bekhet et al., 2008). In caregiver populations, resourcefulness has been studied among caregivers of persons with dementia (Bekhet, 2013; Gonzalez, 1997), African American female caregivers (Picot, Zauszniewski, \& Delgado, 1997), caregivers of frail elders (Fingerman, Gallagher-Thompson, Lovett, \& Rose, 1996), caregivers of persons with serious mental illness (Zauszniewski et al., 2008), primary caregivers of adolescents with schizophrenia (Wang, Rong, Chen, Wei, \& Liu, 2007), and grandmother caregivers (Musil, Jeanblanc, Burant, Zauszniewski, \& Warner, 2013). However, resourcefulness among caregivers of persons with ASD has received little attention (Bekhet, Johnson, \& Zauszniewski, 2012). 
Although caregivers of persons with ASD might benefit from a resourcefulness-training intervention, it is critical to first determine whether the existing measure of resourcefulness, the Resourcefulness Scale (RS) is reliable and valid for this population. To date, the psychometric properties of the RS have not been examined among caregivers of persons with ASD. In the study reported here, we expected to establish the reliability and validity of the RS measure in this population.

The concept of "learned resourcefulness" was initially used by Meichenbaum (1977) to describe attitudes that can be used to cope effectively with external stressors to achieve control over stressful situations. It is conceptualized as an intrapersonal factor that influences human behavior (Meichenbaum, 1977). Eight years later, Meichenbaum developed a stress inoculation program with three major components: (a) self-monitoring of maladaptive thoughts, feelings, and behaviors; (b) emotion regulation and other self-control skills; and (c) problem-solving skills. On the completion of the program, participants were expected to have learned those skills to help them to cope with stress, thereby developing learned resourcefulness, which Meichenbaum equated with psychological antibodies for managing stress, coping effectively, and maintaining health despite confrontation with stressors.

Even though the concept was first introduced by Meichenbaum (1977), many researchers have used Rosenbaum's conceptualization of learned resourcefulness, which describes it as a cognitive-behavioral repertoire of self-control skills, not merely attitudes and perceptions as previously suggested by Meichenbaum. The repertoire of cognitive-behavioral skills constituting resourcefulness is acquired throughout life, through conditioning, modeling, experience, or formal instruction, to help an individual to cope effectively with adversity by controlling the disturbing effects of thoughts, emotions, and feelings to enable the individual to function at an optimal level (Rosenbaum, 1983).

However, the conceptualizations of learned resourcefulness put forward by Meichenbaum (1985) and Rosenbaum $(1980,1990)$ are restricted to self-help strategies that individuals can use independently and without assistance of others. However, research has shown that persons who use self-help and help-seeking skills have the best health outcomes, including better adaptive functioning and life satisfaction than those who used either self-help or help-seeking skills and those who used neither of them (Zauszniewski, 1996). Therefore, skills that involve seeking help from others, for example, family, friends, health-care professionals, have been viewed as equally important as the self-help skills described by Rosenbaum (1990) and incorporated into current resourcefulness theory, which describes two forms of resourcefulness: personal (self-help) and social (help-seeking; Zauszniewski, 2012).

The middle range theory of resourcefulness suggests that there are two forms of resourcefulness: personal (self-help) and social (help-seeking) resourcefulness. The major constructs of the theory are contextual factors, intervening variables or process regulators (i.e., perceptions, cognitions, affect, and motivation), and quality of life outcomes (i.e., physical, psychological, and social functioning; Zauszniewski, 2012).

In this analysis, positive cognitions and perceived burden reflect the process regulators. In addition, psychological well-being and depression reflect quality-of-life outcomes. Previous research has shown that resourcefulness is positively associated with measures of positive cognitions and psychological well-being (Bekhet et al., 2012; Bekhet et al., 2008). Previous research has also shown that 
resourcefulness is negatively correlated with measures of burden and depression (Bekhet, 2013; Bekhet et al., 2012; Choi, Marti, Bruce, \& Hegel, 2013; Peterson, 2013). Therefore, the abovementioned measures were used for construct validation in the study reported here.

Although the concept of resourcefulness was first introduced by Meichenbaum (1977), it was Rosenbaum (1980) who constructed the Self-Control Schedule (SCS) and branded it as a measure of learned resourcefulness. The SCS is composed of 36 items and item responses range from -3 to +3 with no zero point to indicate a neutral response. Rosenbaum (1990) suggested that the calculation of the total score for the SCS may range from -108 to +108 . However, because the previously described scoring method has not been useful for predictive model testing due to the difficulty with score interpretation when positive and negative scores are possible and unequal intervals between items, its scoring has been adjusted in a 6-point scale ranging from 0 (extremely nondescriptive of them) to 5 (extremely descriptive of them; Zauszniewski, 1997). The SCS has been used by many researchers and has been found to be reliable and valid (Rosenbaum, 1980, 1990; Zauszniewski, 1997). However, the SCS does not capture help-seeking skills as other measures have done.

Two measures of social resourcefulness exist: the Social Resourcefulness Scale (SRS; Rapp, Shumaker, Schmidt, \& Naughton, 1995) and the Help-Seeking Resource Scale (HSRS; Zauszniewski, 1996). The 20item SRS measures the frequency of actions taken when an individual needs help that are rated on a 5point scale; scores range from 0 to 80 with higher scores reflecting more frequency use of help-seeking behavior (Rapp et al., 1995). The HSRS contains 12 items that are scaled in a similar way (i.e., 6-point Likert-type scale) as the SCS; scores range from 0 to 60 with higher scores indicating the use of more help-seeking behaviors (Zauszniewski, 1996; Zauszniewski, Lai, \& Tithiphontumrong, 2006)

However, these measures do not measure both forms of resourcefulness with a single measure.

Although the Coping Resources Inventory for Stress (CRIS; Matheny, Aycock, Curlette, \& Junker, 1993) is a 280 -item true-false measure that includes items capturing self-directedness, stress monitoring, tension control, cognitive restructuring, and problem solving, which are aspects of personal resourcefulness, and social support and social ease, which are aspects of social resourcefulness, it is lengthy and therefore burdensome to complete, is specific for measuring resources for coping with stress, and does not measure frequency of use of personal- and social-resourcefulness skills.

Another available scale that has been used with parents is the 33-item Parent Resourcefulness Scale, which assesses the parent's use of positive self-statements, problem-solving strategies, delay of immediate gratification, and other self-control strategies (Chislett \& Kennett, 2007). However, this scale is limited to measuring only self-help skills or personal resourcefulness.

\section{Description of the RS}

The 28-item RS (Zauszniewski et al., 2006) was used to measure individuals' abilities to use self-help (personal resourcefulness) and help-seeking behaviors (social resourcefulness) when facing challenging situations. The RS consists of 28 items and has 2 subscales: 16 items measure personal resourcefulness and 12 items measure social resourcefulness. The scale is rated on a 6-point scoring system ranging from 0 (not at all like me) to 5 (very much like me). The total scores can range from 0 to 140, with higher scores reflecting the greater resourcefulness. The scale's reliability is supported by a Cronbach's alphas of $.83, .79$, and .85 for the total scale and personal and social resourcefulness subscales, 
respectively. Confirmatory factor analysis in older adults has indicated a strong correlation between the two resourcefulness subscales to further support its construct validity $(r=.41, p<.001)$.

The purpose of this study was to measure the psychometric properties of the RS and its subscales that capture personal and social resourcefulness among caregivers of persons with ASD.

\section{Method}

\section{Design and Sample}

This secondary analysis of the psychometric characteristics of the RS with 204 caregivers of persons with ASD used data from two cross-sectional studies of caregivers of persons with ASD (Bekhet et al., 2012; Bekhet \& Zauszniewski, 2013). The first study included 95 caregivers of persons with ASD and aimed at examining the mediator/moderator effects of positive cognitions on the relationship between caregiver burden and resourcefulness (Bekhet et al., 2012). The second study included 109 caregivers and aimed at examining the psychometric properties of a positive-thinking skills scale and used the RS as a validation measure (Bekhet \& Zauszniewski, 2013). The inclusion criteria for both studies were caring for a person with ASD, able to read and understand English, Internet access, and residing in the United States. No potential participants were excluded on the basis of gender, race, or socioeconomic status.

As shown in Table 1, the two samples were similar in demographic characteristics; the majority of caregivers in both studies were females, Caucasian, primary caregivers (a father or a mother), and they were living with the care recipients in the same household. In addition, the caregivers' average age in the first study was 42.8 years $(S D=7.9)$ and their average age in the second study was 42 years $(S D=$ 7). Therefore, the data from the two studies were merged to examine the psychometrics properties of the RS in a larger sample.

Table 1. Demographic Characteristics of the Parent Studies.

\begin{tabular}{|l|l|l|}
\hline & Study $1(n=95)$ & Study $2(n=109)$ \\
\hline Variables & $n(\%)$ & $n(\%)$ \\
\hline Gender & & \\
\hline Females & $92(96.8 \%)$ & $105(96.3 \%)$ \\
\hline Males & $3(3.2 \%)$ & $4(3.7 \%)$ \\
\hline Race & & \\
\hline Caucasian & $88(92.6 \%)$ & $96(88 \%)$ \\
\hline Othersa & $7(7.4 \%)$ & $13(12 \%)$ \\
\hline Relationship to the caregivers & & \\
\hline Father or a mother & $87(91.6 \%)$ & $103(94.5 \%)$ \\
\hline Othersb & $8(8.4 \%)$ & $6(5.5 \%)$ \\
\hline Living situations & & \\
\hline Same household & $94(98.9 \%)$ & $107(98.2 \%)$ \\
\hline Living apart & $1(1.1 \%)$ & $2(1.8 \%)$ \\
\hline
\end{tabular}

${ }^{a}$ African American, Hispanic, Asian.

${ }^{\mathrm{b}}$ Aunts, cousins. 


\section{Data Collection}

In the parent studies, caregiver participants were recruited by convenience sampling from the Interactive ASD Network (IAN) Research registry service (Bekhet et al., 2012; Bekhet \& Zauszniewski, 2013). Institutional Review Board (IRB) approvals for the parent studies were obtained from the university and sent to ASD caregivers by email by IAN that directed ASD caregivers to the Internet website (www.surveymonkey.com) where a consent form and a link to the study questionnaires were housed. In one of the parent studies, those who chose to accept the incentive provided their email address at the end of the survey and were sent a code that could be redeemed for $\$ 25$ at www.Amazon.com (Bekhet et al., 2012). For the second parent study, they were sent a code that could be redeemed for $\$ 15$ at www.Amazon.com (Bekhet \& Zauszniewski, 2013). Email addresses were destroyed after incentive codes were sent to participants. However, for this psychometric analysis, no additional incentive was provided for any of the study participants.

\section{Instruments}

Descriptive data on caregivers of persons with ASD were collected in the two parent studies. In addition, measures of positive cognitions, caregiver burden, depression, and psychological well-being were administered and used in this analysis for construct validation because these concepts are theoretically related to resourcefulness as discussed earlier (Zauszniewski, 2012).

\section{Measures of Construct Validation}

The Depressive Cognition Scale (DCS)

The DCS measures positive cognitions when scoring is not reversed; all items are phrased positively (Zauszniewski, 1995). The scale is rated on a 6-point Likert-type scale ranging from "strongly agree" (5) to "strongly disagree" (0; Zauszniewski, 1995). Total scores range from 0 to 40 with higher scores indicating a greater number of positive cognitions. The scale has been used in previous research to measure positive cognitions (Bekhet, 2013; Bekhet et al., 2008). The 8-item DCS is reliable as evidenced by a Cronbach's alphas of .88 and .84 in samples of dementia caregivers and relocated older adults, respectively (Bekhet et al., 2008). In addition, construct validity of the DCS has been supported by correlations with measures of theoretically related constructs, namely, depression $(r=.54, p<.001)$, resourcefulness $(r=-.37, p<.001)$, and adaptive functioning $(r=-.60, p<.001$; Zauszniewski, Chung, Krafcik, \& Sousa, 2001; Zauszniewski, Picot, Debanne, Wykle, \& Roberts, 2002).

The Zarit Burden Interview (ZBI)

The ZBI was used to measure caregiver burden in this study (Knight, Fox, \& Chou, 2000; Zarit, Reever, \& Bach-Peterson, 1980). The ZBI indicates the burden that caregivers might experience as a result of the caregiving. The 22 items are rated on a 5-point Likert-type scale from "never" (0) to "nearly always" (4). Scores can range from 0 to 88 , and higher scores reflect greater burden. The ZBI is reliable as indicated by Cronbach's alphas ranging from .88 to .92 (Chou, Chu, Tseng, \& Lu, 2003; Thompson, Futterman, Gallagher-Thompson, Rose, \& Lovett, 1993).

The Center for Epidemiologic Studies Depression Scale (CES-D)

Depression was measured by the CES-D (Radloff, 1977). The CES-D is a 20-item Likert-type scale ranging from 0 "rarely or none of the time" to 3 "most or all of the time" (Radloff, 1977). Caregivers are asked to indicate how frequently they experience depressive feelings and behaviors during the past 
week. Scores may range from 0 to 60; higher scores indicate greater depressive symptoms. The CES-D is reliable and valid as evidenced by a Cronbach's alpha of .92 (Ekas, Whitman, \& Shivers, 2009) and by a significant correlations with theoretically related constructs, including the Hamilton Clinician's Rating Scale (Bekhet \& Zauszniewski, 2013; Radloff, 1977).

The General Well-Being Schedule (GWB)

General well-being was measured by the 18-item GWB (Dupuy, 1984). Scores can range from 0 to110, and 14 is subtracted from the total score (Dupuy, 1984). General well-being is evaluated as follows: 0 to 60 indicates severe distress, 61 to 72 indicates moderate distress, and 73 to 110 reflect positive well-being (Dupuy, 1984). Reliability was demonstrated by a Cronbach's alpha of .92, in a sample of Black women (Taylor et al., 2003). Construct validity was evidenced by significant correlations in the expected directions with theoretically related constructs, such as depression and personal feelings ( $r s=$ .66 and .78, respectively; Fazio, 1977).

Psychometric analysis

Data were analyzed using the PASW Statistical Package for the Social Sciences (SPSS) software version 18.0. Psychometric testing of the RS measure involved determining initial estimates of reliability (internal consistency) and construct validity. Preliminary data analysis involved examination of descriptive, including means and standard deviations, as well as frequency distributions. Reliability analyses involved examination of the resourcefulness Cronbach's alphas, inter-item correlations, and item-to-total scale correlations. Construct validity involved factor analysis to determine the presence of the two types of resourcefulness within the RS (i.e., factorial validity) and examination of significant correlations in the expected direction with measures of theoretically related constructs, namely, positive cognitions, burden, depression, and psychological well-being.

\section{Results}

The mean age of caregivers was 42 years; their ages ranged from 23 to 67 years. In all, $96.8 \%$ were females, and the vast majority of the caregivers were Caucasians representing $90.2 \%$ of the total sample; $79.4 \%$ of the caregivers were married, and $14.7 \%$ were either divorced or separated. More than half of the sample (57.8\%) reported an annual income of more than $\$ 45,000$.

\section{Reliability}

The internal consistency of the RS was reflected in a Cronbach's alpha $=.91$. This estimate indicates acceptable internal consistency and exceeds the minimum criterion of .70 (Nunnally \& Bernstein, 1994; Ferketich, 1991). Deletion of any one of the items would not have improved the scale alpha (Table 2). Forty percent of the inter-item correlations were between $r=.30$ and $r=.70$, indicating that the scale measures diverse aspects of personal and social resourcefulness and that the two forms of resourcefulness involve different skills. In addition, the average inter-item correlation found in this study was $(r=.27)$

Table 2. The RS Item Analysis.

\begin{tabular}{|l|l|l|l|l|}
\hline $\begin{array}{l}\text { RS Item } \\
\text { No. }\end{array}$ & Description & $\begin{array}{l}\text { Alpha if Item } \\
\text { Deleted }\end{array}$ & $\begin{array}{l}\text { Item-to-Total } \\
\text { Score Correlations }\end{array}$ & $\begin{array}{l}\text { Communality } \\
\text { Values }\end{array}$ \\
\hline RS-1 & Think about reward & .907 & .404 & .287 \\
\hline
\end{tabular}




\begin{tabular}{|c|c|c|c|c|}
\hline RS-2 & Creative visualization & .905 & .503 & .397 \\
\hline RS-3 & Cognitive reframing & .904 & .583 & .482 \\
\hline RS-4 & Express feelings to others & .904 & .536 & .415 \\
\hline RS-5 & Let others make decision & .905 & .520 & .509 \\
\hline RS-6 & Think about pleasant events & .903 & .629 & .522 \\
\hline RS-7 & Systematic problem solving & .906 & .435 & .462 \\
\hline RS-8 & Go to doctor & .907 & .387 & .278 \\
\hline RS-9 & Think positively & .904 & .591 & .446 \\
\hline RS-10 & Depend on others & .906 & .431 & .617 \\
\hline RS-11 & Keep busy & .904 & .553 & .391 \\
\hline RS-12 & Listen to others & .906 & .467 & .371 \\
\hline RS-13 & Relaxation & .904 & .556 & .464 \\
\hline RS-14 & Get help from others & .906 & .466 & .462 \\
\hline RS-15 & Overcome failure & .903 & .646 & .498 \\
\hline RS-16 & Impulse control & .905 & .497 & .324 \\
\hline RS-17 & Anger management & .907 & .381 & .386 \\
\hline RS-18 & Consider alternatives & .907 & .396 & .368 \\
\hline RS-19 & Borrow from others & .908 & .381 & .207 \\
\hline RS-20 & Talk with others & .903 & .594 & .509 \\
\hline RS-21 & Remain calm & .904 & .537 & .465 \\
\hline RS-22 & Planning behavior & .906 & .416 & .369 \\
\hline RS-23 & Record keeping & .907 & .407 & .268 \\
\hline RS-24 & Ask others to help & .904 & .562 & .480 \\
\hline RS-25 & Allow others to do things & .903 & .593 & .528 \\
\hline RS-26 & Go out with others & .907 & .401 & .292 \\
\hline RS-27 & Be with others & .907 & .434 & .358 \\
\hline RS-28 & Increase concentration & .905 & .513 & .360 \\
\hline
\end{tabular}

Note. RS = Resourcefulness Scale.

To determine the homogeneity of the scale, the corrected item-to-total scale correlations (correlation between each item and total scale, excluding itself) were examined (Ferketich, 1991). As shown in Table 2, all the scale items had item-to-total scale correlations within the recommended range of $r=$ .30 to $r=.70$, indicating the homogeneity of the RS.

\section{Dimensionality and construct validity}

Based on the recommended criteria of 5 to 10 participants per item, the sample of 204 caregivers of persons with autism was adequate to conduct factor analysis of the 28-item RS (Hair, Anderson, Tatham, \& Black, 1998). In addition, the Kaiser-Meyer-Olkin (KMO) value was checked to determine whether the sample was adequate for factor analysis. A value of at least .60 is required (Tabachnick \& Fidell, 2001); in this study, the KMO value was .87, indicating that the sample size was adequate for factor analysis. Bartlett's test of sphericity was significant $(\chi 2=2451.47 ; p<.001)$, indicating that the correlation matrix was appropriate for factor analysis (Strickland, 2003). 
Having met the conditions of adequate sample size and suitability of the correlation matrix, the data from the 28-item RS were subjected to factor analysis. Confirmatory factor analysis was used to examine the construct validity of the 28-item RS because a 2-factor solution had emerged in the original study that tested the psychometric properties of the RS among older adults. Therefore, using the principal axis factoring method of factor extraction with oblique (direct oblimin) rotation and forcing the 28 items onto 2 factors, $41.13 \%$ of the variance in scale items was explained. Similar to the original study that tested and developed the RS in older adults, 16 items loaded on the first factor representing personal resourcefulness and 12 items loaded on the second factor representing social resourcefulness; $21.69 \%$ of the total variance was explained by the first factor, and $19.44 \%$ was explained by the second factor. Of note, none of the items cross-loaded on the other factor (Table 3). Thus, factorial validity was supported by the emergence of the two dimensions of resourcefulness (personal and social) in a confirmatory factor analysis and by substantial intercorrelations between the two subscales $(r=.48, p<.001)$.

Table 3. Confirmatory Factor Analysis of the RS: Two-Factor Solutions.

\begin{tabular}{|l|l|l|l|}
\hline RS Item No. & Description & Factor 1 Loadings & Factor 2 Loadings \\
\hline RS-1 & Think about reward & .535 & \\
\hline RS-2 & Creative visualization & .607 & \\
\hline RS-3 & Cognitive reframing & .640 & \\
\hline RS-4 & Express feelings to others & & .560 \\
\hline RS-5 & Let others make decision & & .713 \\
\hline RS-6 & Think about pleasant events & .622 & \\
\hline RS-7 & Systematic problem solving & .721 & \\
\hline RS-8 & Go to doctor & & .526 \\
\hline RS-9 & Think positively & .546 & \\
\hline RS-10 & Depend on others & & .843 \\
\hline RS-11 & Keep busy & .513 & \\
\hline RS-12 & Listen to others & & .604 \\
\hline RS-13 & Relaxation & .654 & \\
\hline RS-14 & Get help from others & & .703 \\
\hline RS-15 & Overcome failure & .543 & \\
\hline RS-16 & Impulse control & .496 & .682 \\
\hline RS-17 & Anger management & .666 & .594 \\
\hline RS-18 & Consider alternatives & .644 & \\
\hline RS-19 & Borrow from others & & .603 \\
\hline RS-20 & Talk with others & & \\
\hline RS-21 & Remain calm & .678 & \\
\hline RS-22 & Planning behavior & .639 & \\
\hline RS-23 & Record keeping & & \\
\hline RS-24 & Ask others to help & \\
\hline RS-25 & Allow others to do things & & \\
\hline RS-26 & Go out with others & & \\
\hline RS-27 & Be with others & \\
\hline
\end{tabular}




\begin{tabular}{|l|l|l|l|}
\hline RS-28 & Increase concentration & .531 & \\
\hline
\end{tabular}

Note. $\mathrm{RS}=$ Resourcefulness Scale.

The majority of the communality values (82\%) were above .30, and all 28 scale items had strong factor loadings, exceeding the minimum criterion of .30 (Table 2; Nunnally \& Bernstein, 1994; Polit, 1996; Tabachnick \& Fidell, 2001). Construct validity was also supported by significant correlations in the expected direction with measures of positive cognitions. For the total sample $(N=204)$, strong positive correlations in the expected direction were found between the RS and positive cognitions $(r=.58 ; p<$ $.001)$, indicating that higher caregiver resourcefulness was associated with greater positive cognitions. In the sample from Study 1 ( $n=95)$, a significant negative correlation was found between caregiver burden and the RS $(r=-.36, p<.001)$. In the sample from Study 2 ( $n=109)$, significant correlations in the expected direction were found between the RS and measures of caregiver depression and psychological well-being $(r=-.47, p<.001$, and $r=.49, p<.001$, respectively).

\section{Discussion}

This psychometric analysis of the RS provides further evidence for its reliability and validity in a sample that differs from the original one on which the scale was developed. While the sample in the original study comprised older adults living in retirement communities with an average of three chronic health conditions and average age of 81 years, the scale has been used with younger populations with average ages of 58 years (Zauszniewski, Au, \& Musil, 2012) and 46 years (Zauszniewski et al., 2008; Zauszniewski, Bekhet, \& Suresky, 2009). The sample in the study reported here included family caregivers of persons with ASD who were even younger on average, that is, 42 years. These findings suggest that the scale is not age-dependent and is reliable and valid for adults of all ages.

In fact, the reliability analyses conducted in this study of caregivers of persons with ASD indicate greater internal consistency with a Cronbach's alpha of .91 in comparison with the study of elders where the alpha was .85 , a study of family members of persons with serious mental illness where the alpha was 82 (Zauszniewski et al., 2008), and a study of grandmothers raising grandchildren where the alpha was .82 (Zauszniewski et al., 2012). However, the average inter-item correlation found in this study $(r=.27)$ was higher than what was reported in the original psychometric study with elders $(r=$ .18). Similar to the former psychometric analysis, the corrected item-to-total scale correlations for all 28 items on the scale fell into the desired range (Ferketich, 1991).

Evidence for the construct validity of the RS was also supported in this study of family caregivers of persons with ASD. As with other studies in which the RS was used, significant correlations with theoretically related constructs were found. Consistent with resourcefulness and quality-of-life theory (Zauszniewski, 2012), this study found that the RS correlated significantly with measures of burden and cognitions, which are described as process regulators associated with resourcefulness within the theory, and with depressive symptoms and psychological well-being, which reflect indicators of quality of life within the theory. The findings are also consistent with those found in a study of family members of persons with serious mental illness (Zauszniewski et al., 2009) where resourcefulness was found to be associated with measures of depressive cognitions, caregiver burden, and mental health, and with a study of grandmothers raising grandchildren (Zauszniewski et al., 2012) in which resourcefulness was correlated with measures of perceived stress and depressive symptoms. 
The findings from the confirmatory factor analysis in the study reported here closely replicate the findings from the original psychometric study of the RS in the sample of older adults. It is clear that two dimensions of resourcefulness, personal and social, comprise the scale and that these dimensions are correlated but not redundant. Close inspection of the items that load on each of the two factors reveals that the items loading on the personal-resourcefulness factor reflect the use of self-help strategies and the content of the items that loaded on the social SRS focus on help-seeking behaviors. In the study reported here, as in the former study, none of the items loaded on both factors, indicating that the two dimensions of resourcefulness are relevant and the resourcefulness measure is valid for adults of all ages.

In conclusion, this psychometric study of the RS in family caregivers of persons with ASD provides further evidence of the measure's reliability and validity. Further examination of the RS in other samples and using other theoretically related constructs that are consistent with resourcefulness theory is recommended. Because resourcefulness is believed to play an important role in preserving and protecting health and quality of life (Zauszniewski, 2012), a reliable and valid measure is essential for determining one's level of resourcefulness and the degree to which one may benefit from an intervention that teaches the self-help and help-seeking skills constituting personal and social resourcefulness, respectively (Zauszniewski et al., 2012).

Limitations of the study include use of a convenience sample of caregivers of persons with ASD who use the Internet; therefore, the results are generalizable only to those ASD caregivers who use the Internet. However, the advantage of using the Internet was the ability to recruit a national sample of ASD caregivers. Another limitation is that this study was a secondary analysis of existing data. So, we were limited to the use of the existing measures for validation, and, consequently, convergent validity could not be assessed. Future studies might consider adding another resourcefulness measure to assess the same purported construct of resourcefulness. In addition, it is documented in the literature that incentives could be an issue related to the reliability and validity of the data. However, it should be noted that the incentive was given for the parent study and not for this specific analysis that the study participants could not have anticipated. Therefore, it is less of a concern with this analysis than it might have been for the parent study.

Finally, it was impossible to know whether the same caregivers participated in both studies. It is unlikely that this could have happened because the two studies were collected in two different points of time. In addition, participants were recruited by convenience sampling from the IAN, which has consented approximately 15,000 parents of children with ASD. Given the large number of parents participating in the IAN and the considerably small sample sizes in both studies, along with different time points, it is unlikely that the same caregivers participated in both studies. Although the sampling method through the ASD network offers a great opportunity for reaching a very large number of potential study participants, this could be one of the limitations of using that network.

This study has implications for practice. The RS can be used by nurses and health-care professionals to assess the level of resourcefulness among caregivers of persons with ASD. Because the RS measures personal and social resourcefulness, nurses and health-care professionals will be able to assess both aspects and to determine the degree to which caregivers may benefit from an intervention that teaches the self-help and help-seeking skills constituting personal and social resourcefulness, 
respectively. In fact, assessing caregivers' frequent use of self-help and help-seeking behaviors will help early detection and prevention of burden and the subsequent anxiety and depressive symptoms that might develop as a result of caregiving and not using the self-help and the help-seeking strategies. The RS will help us to identify which of the resourcefulness skills are used by the caregivers so they can be reinforced and which skills have not been used so they can be taught to attain a better quality of life for ASD caregivers. Interventions to enhance self-help and help-seeking behaviors might also be directed toward those ASD caregivers who are at risk of developing burden, such as those who have recently learned about their child's diagnosis. Teaching the caregivers personal and social resourcefulness early will help to protect their health and quality of life so that they can continue providing optimal care to their children.

\section{Declaration of Conflicting Interests}

The author(s) declared no potential conflicts of interest with respect to the research, authorship, and/or publication of this article.

\section{Funding}

The author(s) disclosed receipt of the following financial support for the research, authorship, and/or publication of this article: The parent studies are funded by the American Psychiatric Nurses Foundation (APNF) Grant 74614 and by the Way Klinger Young Scholar Award from Marquette University. Both grants were awarded to the principal investigator (Dr. Abir K. Bekhet).

\section{References}

Altiere, M. J., Von Kluge, S. (2009). Searching for acceptance: Challenges encountered while raising a child with autism. Journal of Intellectual \& Developmental Disability, 34, 142-152.

American Psychiatric Association . (2000). Diagnostic and statistical manual of mental disorders (4th ed., text rev.). Washington, DC: Author.

Bekhet, A. (2013). Effects of positive cognitions and resourcefulness on caregiver burden among caregivers of persons with dementia. International Journal of Mental Health Nursing, 22, 340346.

Bekhet, A., Johnson, N., Zauszniewski, J. A. (2012). Effects on resilience of caregivers of persons with autism spectrum disorder: The role of positive cognitions. Journal of the American Psychiatric Nurses Association, 18, 337-344.

Bekhet, A., Zauszniewski, J. (2013). Measuring use of positive-thinking skills scale: Psychometric testing of a new scale. Western Journal of Nursing Research, 35, 1074-1093.

Bekhet, A., Zauszniewski, J. A., Wykle, M. (2008). Milieu change and relocation adjustment in elders. Western Journal of Nursing Research, 30, 13-29.

Benson, P., Karlof, K., Siperstein, G. (2008). Maternal involvement in the education of young children with autism spectrum disorders. Autism, 12, 47-63.

Boonpongmanee, C., Zauszniewski, J. A., Morris, D. L. (2003). Resourcefulness and self-care in pregnant women with HIV. Western Journal of Nursing Research, 25, 75-92.

Carbone, P., Behl, D., Azor, V., Murphy, N. (2010). The medical home for children with autism spectrum disorders: Parent and pediatrician perspectives. Journal of Autism and Developmental Disorders, 40, 317-324. 
Carter, A. S., Martinez-Pedraza, F., Gray, S. A. (2009). Stability and individual change in depressive symptoms among mothers raising young children with ASD: Maternal and child correlates. Journal of Clinical Psychology, 65, 1270-1280.

Centers for Disease Control and Prevention . (2012). Prevalence of autism spectrum disordersAutism and developmental disabilities monitoring network. Retrieved from http://www.cdc.gov/ncbddd/autism/addm.html

Chislett, G., Kennett, D. J. (2007). The effects of the nobody's perfect program on parenting resourcefulness and competency. Journal of Child and Family Studies, 16, 473-482.

Choi, N. G., Marti, C. N., Bruce, M. L., Hegel, M. T. (2013). Depression in homebound older adults: Problem-solving therapy and personal and social resourcefulness. Behavior Therapy, 44, 489500.

Chou, K. R., Chu, H., Tseng, C. L., Lu, R. B. (2003). The measurement of caregiver burden. Journal of Medical Science, 23, 73-82.

Dupuy, H. J. (1984). The psychological general wellbeing index. In Wenger, N. K., Mattson, M. E., Furberg, C. D., Elinson, J. (Eds.), Assessment of quality of life in clinical trials of cardiovascular therapies (pp. 170-183). New York, NY: Le Tacq.

Ekas, N. V., Lickenbrock, D. M., Whitman, T. L. (2010). Optimism, social support, and wellbeing in mothers of children with autism spectrum disorder. Journal of Autism and Developmental Disorders, 40, 1274-1284.

Ekas, N. V., Whitman, T. L., Shivers, C. (2009). Religiosity, spirituality, and socioemotional functioning in mothers of children with autism spectrum disorder. Journal of Autism and Developmental Disorders, 39, 706-719.

Fazio, A. F. (1977). A concurrent validational study of the NCHS' general well-being schedule. Hyattsville, MD: Department of Health, Education, and Welfare, Public Health Service, Heath Resources Administration, National Center for Health Statistics.

Ferketich, S. (1991). Focus on psychometrics: Aspects of item analysis. Research in Nursing and Health, 14, 165-168.

Fingerman, K. L., Gallagher-Thompson, D., Lovett, S., Rose, J. (1996). Internal resourcefulness, task demands, coping, and dysphoric affect among caregivers of the frail elderly. International Journal of Aging \& Human Development, 42, 229-248.

Gonzalez, E. W. (1997). Resourcefulness, appraisals, and coping efforts of family caregivers. Issues in Mental Health Nursing, 18, 209-227.

Hair, J. F., Anderson, R. E., Tatham, R. L., Black, W. C. (1998). Multivariate data analysis (5th ed.). Englewood Cliffs, NJ: Prentice Hall.

Huang, C. Y., Guo, S. E., Hung, C. M., Shih, S. L., Lee, L. C., Hung, G. C., Huang, S. M. (2010). Learned resourcefulness, quality of life, and depressive symptoms for patients with breast cancer. Oncology Nursing Forum, 37, E280-E287.

Karst, J. S., Van Hecke, A. V. (2012). Parent and family impact of autism spectrum disorders: A review and proposed model for intervention evaluation. Clinical Child and Family Psychology, 15, 247-277.

Knight, B. G., Fox, L. S., Chou, C. (2000). Factor structure of the burden interview. Journal of Clinical Geropsychology, 6, 249-258.

Matheny, K. B., Aycock, D. W., Curlette, W. L., Junker, G. N. (1993). The coping resources inventory for stress: A measure of perceived resourcefulness. Journal of Clinical Psychology, 49, 815830. 
Matson, J. L., Fodstad, J. C. (2009). The treatment of food selectivity and other feeding problems in children with autism spectrum disorders. Research in Autism Spectrum Disorders, 3, 455-461.

Meichenbaum, B. (1977). Cognitive-behavior modification: An integrative approach. New York, NY: Plenum Press.

Meichenbaum, B. (1985). Stress inoculation training. New York, NY: Pergamon Press.

Montes, G., Halterman, J. (2007). Psychological functioning and coping among mothers of children with autism: A population based study. Pediatrics, 119, e1040-e1046.

Musil, C. M., Jeanblanc, A. B., Burant, C. J., Zauszniewski, J. A., Warner, C. B. (2013). Longitudinal analysis of resourcefulness, family strain, and depressive symptoms in grandmother caregivers. Nursing Outlook, 61, 225-234.

Nunnally, J. C., Bernstein, I. H. (1994). Psychometric theory. New York, NY: McGraw-Hill.

Peterson, K. (2013). Learned resourcefulness, danger in intimate partner relationships, and mentalhealth symptoms of depression and PTSD in abused women. Issues in Mental Health Nursing, 34, 386-394.

Phetrasuwan, S., Miles, M. (2009). Parenting stress in mothers of children with autism spectrum disorders. Journal of Pediatric Nursing, 14, 157-165.

Picot, S. J., Zauszniewski, J. A., Delgado, C. (1997). Cardiovascular responses of African-American female caregivers. Journal of the National Black Nurses' Association, 9, 3-21.

Polit, D. F. (1996). Data analysis and statistics for nursing research. Stamford, CT: Appleton \& Lange.

Radloff, L. S. (1977). The CES-D Scale: A self-report depression scale for research in the general population. Applied Psychological Measurement, 1, 385-401.

Rapp, S. R., Shumaker, S., Schmidt, S., Naughton, M. (1995). Social resourcefulness scale: Development and preliminary validation. Unpublished manuscript.

Rosenbaum, M. (1980). A schedule for assessing self-control behaviors: Preliminary findings. Behavior Therapy, 11, 109-121.

Rosenbaum, M. (1983). Learned resourcefulness as a behavior repertoire for the self-regulation of internal events: Issues and speculations. In Rosenbaum, M., Franks, C. M., Jaffe, Y. (Eds.), Perspectives on behavior therapy in the eighties (pp. 54-73). New York, NY: Springer.

Rosenbaum, M. (1990). Learned resourcefulness on coping skills, self-control, and adaptive behavior. New York, NY: Springer.

Strickland, O. L. (2003). Using factor analysis for validity assessment: Practical considerations. Journal of Nursing Measurement, 11, 203-205.

Tabachnick, B. G., Fidell, L. S. (2001). Using multivariate statistics. Boston, MA: Allyn \& Bacon.

Taylor, J. E., Poston, W. S., Haddock, C. K., Blackburn, G. L., Heber, D., Heymsfield, S. B., Foreyt, J. P. (2003). Psychometric characteristics of the General Well-Being Schedule (GWB) with AfricanAmerican women. Quality of Life Research, 12, 31-39.

Thompson, E. H., Futterman, A. M., Gallagher-Thompson, D., Rose, J. M., Lovett, S. B. (1993). Social support and caregiving burden in family caregivers of frail elders. Journal of Gerontology, 48, S245-S254.

Wang, S. H., Rong, J. R., Chen, C. C., Wei, S. J., Liu, K. C. (2007). A study of stress, learned resourcefulness, and caregiver burden among primary caregivers of schizophrenic adolescents. Hu Li Za Zhi: The Journal of Nursing, 54, 37-47.

Zarit, S. H., Reever, K. E., Bach-Peterson, J. (1980). Relatives of the impaired elderly: Correlates of feelings of burden. Gerontologist, 20, 649-655. 
Zauszniewski, J. A. (1995). Development and testing of a measure of depressive cognition in older adults. Journal of Nursing Measurement, 3, 31-41.

Zauszniewski, J. A. (1996). Self-help and help-seeking behavior patterns in healthy elders. Journal of Holistic Nursing, 14, 223-236.

Zauszniewski, J. A. (1997). Evaluation of measure of learned resourcefulness for elders. Journal of Nursing Measurement, 5, 71-86.

Zauszniewski, J. A. (2012). Resourcefulness. In Fitzpatrick, J. J., Kazer, M. (Eds.), Encyclopedia of nursing research (pp. 448-449). New York, NY: Springer.

Zauszniewski, J. A., Au, T. Y., Musil, C. M. (2012). Resourcefulness training for grandmothers raising grandchildren: Is there a need? Issues in Mental Health Nursing, 33, 680-686.

Zauszniewski, J. A., Bekhet, A. K., Suresky, M. J. (2008). Factors associated with perceived burden, resourcefulness, and quality of life in female family members of adults with serious mental illness. Journal of the American Psychiatric Nurses Association, 14, 125-135.

Zauszniewski, J. A., Bekhet, A. K., Suresky, M. J. (2009). Relationships among stress, depressive cognitions, resourcefulness, and quality of life in female relatives of seriously mentally ill adults. Issues in Mental Health Nursing, 30, 142-150.

Zauszniewski, J. A., Chung, C. (2001). Resourcefulness and health practices of diabetic women. Research in Nursing \& Health, 24, 113-121.

Zauszniewski, J. A., Chung, C., Chang, H. J., Krafcik, K. (2002). Predictors of resourcefulness in schoolaged children. Issues in Mental Health Nursing, 23, 385-401.

Zauszniewski, J. A., Chung, C., Krafcik, K. (2001). Social cognitive factors predicting the health of elders. Western Journal of Nursing Research, 23, 490-503.

Zauszniewski, J. A., Chung, C., Krafcik, K., Sousa, V. D. (2001). Psychometric testing of the Depressive Cognition Scale in women with type 2 diabetes. Journal of Nursing Measurement, 9, 61-72.

Zauszniewski, J. A., Lai, C. Y., Tithiphontumrong, S. (2006). Development and testing of the Resourcefulness Scale for Older Adults. Journal of Nursing Measurement, 14, 57-68.

Zauszniewski, J. A., Picot, S. J. F., Debanne, S., Wykle, M., Roberts, B. L. (2002). Psychometric characteristics of the Depressive Cognition Scale in African-American women. Journal of Nursing Measurement, 10, 83-95. 